\section{CIRCADIAN ORGANIZATION}

The Physiological Clock

Endogenous Diurnal Rhythms and Biological Chronometry. By Erwin Bünning. Pp. vi +145 . (Berlin: Springer-Verlag, 1964.) 19 D.M.

FHIS English translation of the second (1963) edition 1 of "Die Physiologische Uhr" has been brought up to date by the author and is quite indispensable for any biologist interested in the rhythmical aspects of organisms and their manifold theoretical and practical implications. It is more comprehensive and less controversial than other recent books and reviews of the subject. Although it cannot rival the bulk of information presented at three symposia held during the past few years (25th Cold Spring Harbor symposium, 1960; 39th Ross Conference on Pediatrics, Ohio, 1961 ; Conference on Biological Rhythms of the New York Academy of Science, 1962), it has the advantage of boing written by a single author, who has been working on the subject for more than 30 years.

The old-fashioned title of the book should not mislead the reader into believing that endogenous rhythms of approximately $24 \mathrm{~h}$ period length can only be produced by highly specialized machinery, such as the neurocrine systems of vertebrates and arthropods or the joints of leaves of higher plants. Bünning makes it abundantly clear that oscillations which Halberg (1959) has named circadian (from circa diem, about a day) occur at most levels of organization, in fungal mycelia and unicellular algae, in birds and flowering plants, and in the social organization of the bees and of man. They affect a multitude of metabolic, locomotor, epigenetic and sexual activities, can be demonstrated by measuring all sorts of parameters and in Nature are synchronized by physical, chemical, biological or social cues, which all derive from the rotation of the Earth. The length of time a circadian rhythm may persist after removal of rhythmic time cues depends on the kind of organism, the function observed and certain environmental factors. According to the different degree of centralization of flowering plants and higher animals a small part of a leaf may show an endogenous rhythm of about $24 \mathrm{~h}$ in its $\mathrm{CO}_{2}$ output, whereas an isolated limb, organ or tissue of a metazoon is unlikely to show any trace of circadian rhythm-with the possible exception of larger parts of the nervous and endocrine systems, which are the 'masterclocks' of these organisms.

The kinds of time cues or synchronizers, the degree of autonomy and interdependence of the various behavioural and organ rhythms, and many interactions of the circadian organization not only with diurnal rhythms but also with the tidal, lunar and seasonal fluctuations, form the principal subject matter of Bünning's book. While to a superficial glance this may appear as somewhat of a medley, it will repay the reader to follow the author's lead when he tries to fit this diverse material into the mathematical, physiological and ecological generalizations which, as his own experimental successes have shown, have considerable predictive power.

Bünning's book indicates one of the profound but nearly imperceptible 'sea changes' in biology; one which is about to sweep away many cherished, and in their time beneficial, concepts of nineteenth-century physiology. One of these is excessive biological atomism, the idea that in the end' life will be explicable in those chemical and physical concepts which are derived from the results of isolating and destructive methods. Obviously the study of organization, circadian or otherwise, does not lend itself to this approach. To paraphrase an old gibe: when dissecting an animal a biological clock, like the mind, is just not among the organs, though-again like the mind-time-keeping may have a decided affinity to special organs.

Another change concerns the concept of homcostasis, Claude Bernard's grand idea which in its petrified form has been for half a century a millstone round tho neck of physiologists, clinicians and even geneticists. The conviction that 'the organism' strives at maintaining many physiological parameters at a constant level has blinded biologists to the universal existence of oscillations and their functions and also has distorted the aims of some laboratory practices and of therapeutic procodures. Constant temperature or illumination-though compatible with the bare existence of many domesticated strains in insects, rodents or birds-nevertheless introduces strains of their lives and does not produce specimens which are suitable for a host of behavioural experiments. The relative disregard (compared with such obvious factors as heat, hunger or infection) of the importance of the hour of the day for personal habite, shift work, hospital ward practice, or air travel has been at the root of much distress. It all stems from neglecting man's eircadian organization, which to such 'quacks' of the eighteenth-century as Hufeland was one of the fundamentals of health. With the improvement of research methods the time aspects of life, and the everwidening field of their application, are becoming increasingly important; over half an insulin dose can be saved for certain patients by administering it at the right hour; pheromones produced by the females of some moth species attract the males only during the three hours after midnight; the success of growing chrysanthemums and of producing eggs depends to a considerable extent on the light regimen during the day's $24 \mathrm{~h}$-and so on.

It is perhaps paradoxical that the advent of the space age should coincide with the renewed interest of biologists in such old-fashioned terrestrial phenomena as the days, the tides and the seasons; and that some of their work should be supported by funds for space research. But, just as rockets and satellites have revived interest in celestial mechanics, so does the prospect held out by these vehicles of facing life without the accustomed changes of the hours or seasons revive interest in the potentialities and constraints which are the consequence of the circadian organization of ourselves and our fellow creatures.

H. KatMUS

\section{ASPECTS OF CORTICOSTEROID STRUCTURE AND METABOLISM}

Structure and Metabolism of Corticosteroids

Edited by Jorge R. Pasqualini and Max F. Jayle. (Proceed. ings of a Symposium held in Paris, 5-6 July 1963, and organized by the Faculté de Médecine, Laboratoire de Chimie Biologique.) Pp. $x+168$. (London: Academic Press, Inc. (London), Ltd.; New York: Academic Press, Inc., 1964.) $35 s$.

THE collection of sixteen papers which constitute Structure and Metabolism of Corticosteroids follows no well-defined pattern, and the editors have not found it an easy task in deciding on the best grouping to adopt in preparing it. Part 1 dealing with structural problems has only two chapters, a detailed account by Caspi of work at the Worcester Foundation in which he emphasizes the usefulness of nuclear magnetic resonance spectra, and a contribution by Kellio on the means of differentiating betweon two types of conjugate, for example, $\mathrm{C}_{3^{-}}$and $\mathrm{C}_{21}$-glucuronosides.

The largest set of contributions are those in Part 2 entitled "Corticosteroid Metabolism in Vivo and Vitro", where we find much more on the subject of conjugation. Oertel adduces here further evidence to support his previously published work on those non-polar solvolysable steroid conjugates styled "sulphatidyl" steroids. Conjugation in urine and plasma is also the topic dealt with by the joint editors, who have accumulatod an improssive array of evidence on which to formulato a set of rules governing the rolationship between structure and type of conjugation. Sulphate conjugation is the subject of the paper by Tamm and Voigt, who offer an explanation of the curious 